\title{
Extracranial Landmarks for Surgical Skull Base Approaches
}

\author{
Puntos de Referencia Extracraneales para Abordajes Quirúrgicos de la Base del Cráneo
}

Esin Ozsahin'; Huseyin Erdem²; Neslihan Boyan² \& Ozkan Oguz ${ }^{2}$

\begin{abstract}
OZSAHIN, E.; ERDEM, H.; BOYAN, N. \& OGUZ, O. Extracranial landmarks for surgical skull base approaches. Int. J. Morphol., 39(6):1669-1672, 2021.

SUMMARY: Surgical operations regarding to skull base are challenging and reliable anatomical landmarks are required. There is a lack of knowledge on anatomical variations in this region. The aim of this study was to determine the safe extracranial landmarks for surgical approach to the skull base. In this study, 23 adult dry skulls were evaluated: the age and sex of the specimens were unknown. All measurements were taken from external surface of inferior aspect of the skull by using digital calipers accurate to $0.01 \mathrm{~mm}$. In right and left sides; the distances between the external acoustic meatus (EAM) and the following anatomical landmarks were measured: articular tubercle (AT); anterior margin of squamous suture (ASS); superior margin of squamous suture (SSS); posterior margin of squamous suture (PSS); end point of styloid process (SP); midpoints of pterygomaxillary fissure (PMF); foramen ovale (FO); foramen spinosum (FS); and of carotid canal (CC).The distances of the external acoustic meatus to the anatomical structures on the right and left sides were: EAM-SP; 24.24 $\pm 3.19 \mathrm{~mm}, 23.16 \pm 3.17 \mathrm{~mm}$; EAM-PMF; 46.56 $\pm 4.51 \mathrm{~mm}, 46.25 \pm 3.96 \mathrm{~mm}$; EAM-FO; $27.57 \pm 2.87 \mathrm{~mm}, 28.70 \pm 2.85 \mathrm{~mm}$; EAM-FS; $22.53 \pm 3.19 \mathrm{~mm}, 22.72 \pm 3.47 \mathrm{~mm}$; EAM-CC; $17.35 \pm 3.56 \mathrm{~mm}, 17.19 \pm 3.39 \mathrm{~mm}$; EAM-AT; $19.31 \pm 3.79 \mathrm{~mm}, 18.95 \pm 3.42 \mathrm{~mm}$; EAM-ASS; $43.14 \pm 4.80 \mathrm{~mm}, 46.82 \pm 4.61 \mathrm{~mm}$; EAM-SSS; $49.17 \pm 4.74 \mathrm{~mm}, 48.83 \pm 3.34 \mathrm{~mm}$ and EAM-PSS; $36.15 \pm 4.24 \mathrm{~mm}, 35.39 \pm 4.25$ $\mathrm{mm}$, respectively. We think that the findings obtained from this study related to external acoustic meatus can be an important reference for surgical anatomy and surgical procedures in skull base.
\end{abstract}

KEY WORDS: External acoustic meatus; Skull base; Surgical anatomy; Surgical approach.

\section{INTRODUCTION}

In skull base surgery; the middle cranial fossa procedure is widely accepted to be one of the most important and difficult approaches. Theoretically; hearing function may be kept intact, therefore surgeons prefer to extend the dissection site and increase indications (Aristegui et al., 1994; Chopra et al., 2003; Tanriover et al., 2009).

Middle skull base includes one of the most important anatomical areas for surgical skull base approaches. The middle fossa is limited between the sphenoid ridge and the petrous ridge. Various neurovascular elements are passing through the middle skull base, and the anatomy of this region is further complicated due to the location of important structures within the temporal bone (Edwards et al., 2018; Peris-Celda et al., 2019). The objective of this study is to describe the precise and accurate guiding for the middle fossa surgery, especially in identifying the external acoustic meatus (EAM).
The middle fossa approach has quite intricate difficulties by reason of the many vital structures that are located in a very small operation area. To avoid damage in the middle fossa; distances between each structures must be measured and also be examined by morphological perspective (Rhoton Jr., 2000; Sennaroglu \& Slatterry, 2003; Jung et al., 2004).

The external acoustic meatus (EAM), styloid process (SP), pterygomaxillary fissure (PMF), foramen ovale (FO), foramen spinosum (FS), carotid canal (CC), articular tubercle (AT) and squamous suture has close relationships with important neurovascular structures. Additionally each of these structures are considered as an important landmark. However, their clinical anatomy has not been studied in detail. On the other hand, it may be difficult to observe the neural structures, in case of a deformation or a possible tumor invasion (Lang et al., 1984; Krayenbühl et al., 2008; Patil et al., 2013).

\footnotetext{
${ }^{1}$ Baskent University, Faculty of Medicine, Department of Anatomy, Adana, Turkey.

${ }^{2}$ Cukurova University, Faculty of Medicine, Department of Anatomy, Adana, Turkey.
} 


\section{MATERIAL AND METHOD}

In this study, 23 adult dry skulls were evaluated: the age and sex of the specimens were unknown. All measurements were taken from external surface of inferior aspect of the skull by using digital calipers accurate to 0.01 $\mathrm{mm}$. In right and left sides; the distances between the external acoustic meatus (EAM) and the following anatomical landmarks were measured: end point of styloid process (SP); midpoint of pterygo maxillary fissure (PMF); midpoint of foramen ovale (FO); midpoint of foramen spinosum (FS); midpoint of carotid canal (CC); articular tubercle (AT); anterior margin of squamous suture (ASS); superior margin of squamous suture (SSS) and posterior margin of squamous suture (PSS) (Figs.1 and 2).

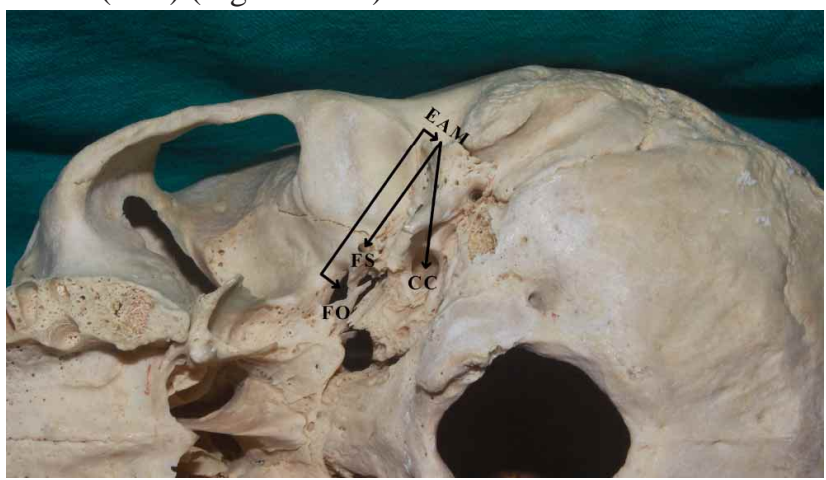

Fig. 1. The distances between the external acoustic meatus (EAM) and the anatomical landmarks of the skull base. EAM-FO: EAMmidpoint of foramen ovale (FO); EAM-FS: EAM-midpoint of foramen spinosum (FS); EAM-CC: EAM-midpoint of carotid canal (CC).

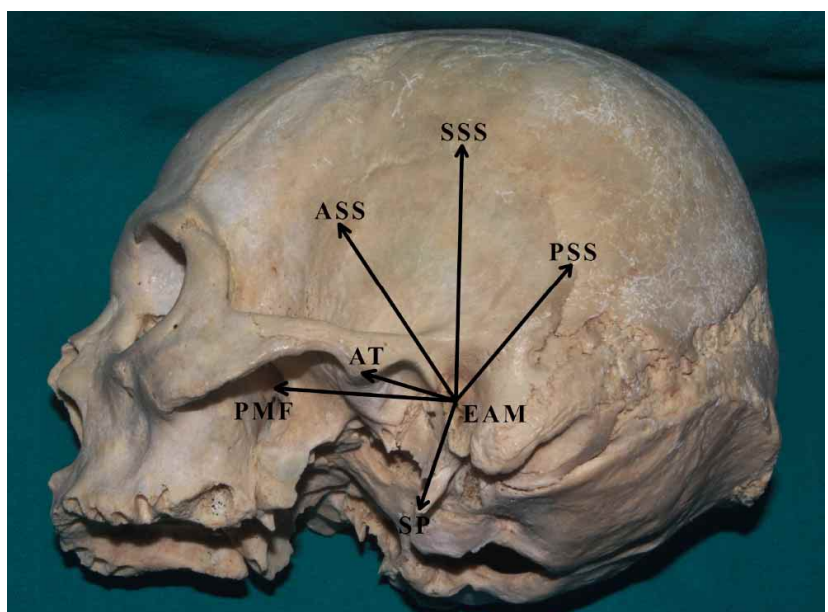

Fig. 2. The distances between the external acoustic meatus (EAM) and the anatomical landmarks of the skull base. EAM-SP: EAM-end point of styloid process (SP); EAM-PMF: EAM-midpoint of pterygo maxillary fissure (PMF); EAM-AT: EAM-articular tubercle (AT); EAM-ASS: EAM-anterior margin of squamous suture (ASS); EAMSSS: EAM-superior margin of squamous suture (SSS); EAM-PSS: EAM-posterior margin of squamous suture (PSS).

\section{RESULTS}

The distances of the external acoustic meatus to the anatomical structures on the right and left sides are expressed in Table I.

Table I. Measurements between the external acoustic meatus and the anatomical structures on the right and left sides. Expressed in mm.

\begin{tabular}{lcccc}
\hline \multirow{2}{*}{ Parameters } & \multicolumn{2}{c}{ Right Side } & \multicolumn{2}{c}{ Left Side } \\
\cline { 2 - 5 } & Ranges & Mean \pm SD & Ranges & Mean \pm SD \\
\hline EAM-SP & $15-30$ & $24.24 \pm 3.19$ & $17-30$ & $23.16 \pm 3.17$ \\
EAM-PMF & $40-57$ & $46.56 \pm 4.51$ & $40-51$ & $46.25 \pm 3.96$ \\
EAM-FO & $23-33$ & $27.57 \pm 2.87$ & $24-33$ & $28.70 \pm 2.85$ \\
EAM-FS & $17-29$ & $22.53 \pm 3.19$ & $17-31$ & $22.72 \pm 3.47$ \\
EAM-CC & $11-24$ & $17.35 \pm 3.56$ & $10-26$ & $17.19 \pm 3.39$ \\
EAM-AT & $11-26$ & $19.31 \pm 3.79$ & $12-26$ & $18.95 \pm 3.42$ \\
EAM-AS S & $32-55$ & $43.14 \pm 4.80$ & $38-57$ & $46.82 \pm 4.61$ \\
EAM-SSS & $42-63$ & $49.17 \pm 4.74$ & $42-49$ & $48.83 \pm 3.34$ \\
EAM-PSS & $30-45$ & $36.15 \pm 4.24$ & $29-43$ & $35.39 \pm 4.25$ \\
\hline
\end{tabular}

EAM-SP: external acoustic meatus (EAM)-end point of styloid process (SP); EAM-PMF: EAM-midpoint of pterygo maxillary fissure (PMF); EAM-FO: EAM-midpoint of foramen ovale (FO); EAM-FS: EAM-midpoint of foramen spinosum (FS); EAM-CC: EAM-midpoint of carotid canal (CC); EAMAT: EAM- articular tubercle (AT); EAM-ASS: EAM-anterior margin of squamous suture (ASS); EAM-SSS: EAM-superior margin of squamous suture (SSS); EAM-PSS: EAM-posterior margin of squamous suture (PSS).

\section{DISCUSSION}

Surgical approaches to the skull base need to be guided by external landmarks regarding to temporal and sphenoid bones. This guiding strategy allows the surgeons to identify the middle fossa and to avoid postoperative or intraoperative complications. Besides anatomical variations should be considered to enhance the success of surgical interventions. Furthermore, it is particularly important to keep in mind the anatomical variations, for the benefit of individuals whose middle fossa regions were manifested by a variety of pathologies or with evidence that indicated the trauma (Kaylie et al., 2006; Tanriover et al.; Peris-Celda et al., 2019). This manuscript defines the important landmarks of the middle fossa to avoid any iatrogenic injuries.

There are many descriptions of the middle fossa foramina together with its components, but there is very little data on relevant surgical anatomical topic and to our knowledge none of them focuses on the relationships

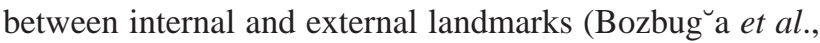
1998; Chopra et al.; Miller \& Pensak, 2003; Peris-Celda et al., 2019). There are various surgical approaches to expose numerous pathologies originating from the middle fossa

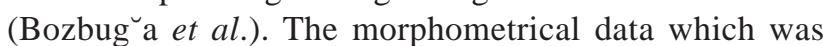
determined to focus on surgical anatomy, and also important 
external landmarks of the middle fossa are needed to be considered on classical middle fossa surgery (Peris-Celda et al., 2019). EAM is an important anatomical reference and a very significant point regarding to skull base approaches. The middle cranial fossa operations guided with specific anatomical landmarks are less time consuming and results with minimum retraction in the incision area or deeper operated regions. The EAM is the main external landmark which was discussed in this study. The EAM is a useful reference point, especially before the skin incision. After the skin incision the zygomatic root clearly be exposed (Roland et al., 1991; Sennaroglu \& Slatterry; Peris-Celda et al., 2019).

Professor Rhoton, has been the forerunner of the "seethrough vision" concept in neurosurgery that is related to being able to locate deep critical structures by examining the superficial planes with appropriate knowledge of surgical anatomy (Rhoton Jr., 2011; Peris-Celda et al., 2019). This concept helps the surgeons all through the operation period with planning, execution and integration of surgical navigation. Careful study of the anatomy must go along with surgical anatomical knowledge (Komune et al., 2017).

The dura mater can be dissected to inferiorly to feel the floor of the middle fossa and can be determined as the inferior aspect of the craniotomy if necessary. In this process; burr holes will not be placed in undesirable locations such as the transverse-sigmoid junction, above the tentorium posterior to the petrous bone, or over the mastoid process. In this study the gender or ethnicity of the dry skulls were unknown. This limitation can alter the management of our results. Measurements can be variable, but the locations associated with external structures is mostly constant. We strongly suggest that in order to adapt the previously known general anatomical knowledge of the specific anatomy of the patient and the pathology, detailed preoperative examinations should be performed. We think neuronavigation is a valuable tool, but may not always be suitable throughout the process and must be assumed as a supplement for the anatomical knowledge but not as a substitution. Furthermore, it is still not an efficient technique to locate small adjacent neurovascular structures, by neuronavigation (Kaylie et al.; Peris-Celda et al., 2013; PerisCelda et al., 2019). In this study we also aimed to help to the neuronavigation process by determining the distances between EAM and various important landmarks. We believe, the neurovascular structures that settled in the middle cranial fossa or passing through this region can be precisely located with the contribution of the data which we presented in this study. Although Professor Rhoton has studied neuronavigation techniques in detail, and he quoted that 'the best navigation is the surgical anatomy in the mind of the surgeon in order to make surgery more accurate, gentle, and safe for our patients" (Rhoton Jr., 2011).

Peris-Celda et al. (2019) reported that the distances of the EAM to the anatomical landmarks on the right and left sides were: EAM-FO; 20.6 (9.6-29) mm; EAM-FS; 14.7 (5.8-20.9) mm; EAM-ASS; 36.6 (27.1-43.9) mm; EAMSSS; 39.6 (29-47.8) mm; EAM-PSS; 24 (11.9-38.1) mm. It was observed that there is a slight difference between the results of the study conducted with Peris-Celda et al. (2019) and our results presented in the current study. This discrepancy may result from different ethnicity and the geographical regions of the skulls analyzed.

Our results suggest that the temporal line or slightly inferior to it, is a safe beginning for the superior portion of the mastoidectomy. Surgeons should be aware that in some cases the dura can be located at this point (Miller \& Pensak; Patil et al.; Peris-Celda et al., 2019). We believe that this study can be implemented to a novel neuronavigation-based research method to quantitatively compare different approaches in the middle cranial fossa. After adapting our data as a guide in neuronavigational procedures and gaining experience, outcomes can be considered in clinical implementations.

We believe our morphometric measurements can provide and contribute to a safe and a rapid approach to skull base. Therefore surgeons need to have an extensive anatomical knowledge of this area to decide the safe and accurate approach technique in surgical procedures.

OZSAHIN, E.; ERDEM, H.; BOYAN, N. \& OGUZ, O. Puntos de referencia extracraneales para abordajes quirúrgicos de la base del cráneo. Int. J. Morphol., 39(6):1669-1672, 2021.

RESUMEN: Las cirugías relacionadas con la base del cráneo son un desafío, las cuales requieren puntos de referencia anatómicos confiables. Existe una falta de conocimiento sobre las variaciones anatómicas en esta región. El objetivo de este estudio fue determinar los puntos de referencia extracraneales seguros para el abordaje quirúrgico de la base del cráneo. En este estudio se evaluaron 23 cráneos secos adultos: se desconocía la edad y el sexo de los ejemplares. Las medidas se tomaron de la superficie externa de la cara inferior del cráneo utilizando calibradores digitales con una precisión de 0,01 mm. En lados derecho e izquierdo se midieron las distancias entre el meato acústico externo (MAE) y los siguientes puntos de referencia anatómicos: tubérculo articular (TA); margen anterior de la sutura escamosa (MASE); margen superior de sutura escamosa (MSSE); margen posterior de sutura escamosa (MPSE); punto final del proceso estiloides (PFPE); puntos medios de la fisura pterigomaxilar (PMFP); foramen oval (FO); foramen espinoso (FE); y del canal carotídeo (CC). Las distancias del meato acústico externo a las estructuras anatómicas de los lados derecho e izquierdo fueron: MAE-PFPE; 24,24 $\pm 3,19$ mm, 23,16 $\pm 3,17$ mm; MAE-PMFP; 
46,56 \pm 4,51 mm, 46,25 $\pm 3,96 \mathrm{~mm} ;$ MAE-FO; 27,57 $\pm 2,87 \mathrm{~mm}$, $28,70 \pm 2,85 \mathrm{~mm}$; MAE-FE; $22,53 \pm 3,19 \mathrm{~mm}, 22,72 \pm 3,47 \mathrm{~mm}$; MAE-CC; $17,35 \pm 3,56 \mathrm{~mm}, 17,19 \pm 3,39 \mathrm{~mm}$; MAE-TA; $19,31 \pm$ $3,79 \mathrm{~mm}, 18,95 \pm 3,42 \mathrm{~mm}$; MAE-MASE; 43,14 \pm 4,80 mm, 46,82 \pm 4,61 mm; MAE-MSSE; 49,17 \pm 4,74 mm, 48,83 $\pm 3,34 \mathrm{~mm}$ y MAE-MPSE; $36,15 \pm 4,24 \mathrm{~mm}, 35,39 \pm 4,25 \mathrm{~mm}$, respectivamente. Creemos que los hallazgos obtenidos de este estudio relacionados con el meato acústico externo pueden ser una referencia importante para la anatomía quirúrgica y los procedimientos quirúrgicos en la base del cráneo.

PALABRAS CLAVE: Meato acústico externo; Base del craneo; Anatomía quirúrgica; Abordaje quirúrgico.

\section{REFERENCES}

Aristegui, M.; Cokkeser, Y.; Saleh, E., Naguib, M.; Landolfi, M.; Taibah, A. \& Sanna, M. Surgical anatomy of the extended middle cranial fossa approach. Skull Base Surg., 4(4):181-8, 1994.

Bozbuga, M.; Öztürk, A.; Ari, Z.; Sahinoglu, K.; Bayraktar, B.; Polat, G. \& Gürel, I. Surgical anatomy of the temporal bone and measurements of the skull base for transpetrosal approaches. Okajimas Folia Anat. Jpn., 75(1):33-9, 1998.

Chopra, R.; Fergie, N.; Mehda, D. \& Liew, L. The middle cranial fossa approach: an anatomical study. Surg. Radiol. Anat., 24(6):348-51, 2003.

Edwards, B.; Wang, J. M.; Iwanaga, J.; Loukas, M. \& Tubbs, R. S. Cranial nerve foramina part I: a review of the anatomy and pathology of cranial nerve foramina of the anterior and middle fossa. Cureus, 10(2):e2172, 2018.

Jung, S. M.; Jang, S. J. \& Ahn, T. H. Microanatomical study of the extradural middle fossa approach for preventing cochlear damage. J. Korean Neurosurg., 36(5):353-7, 2004.

Kaylie, D. M.; Wittkopf, J. E.; Coppit, G.; Warren 3rd, F. M.; Netterville, J. M. \& Jackson, C. G. Revision lateral skull base surgery. Otol. Neurotol., 27(2):225-33, 2006

Komune, N.; Matsushima, K.; Matsuo, S.; Safavi-Abbasi, S.; Matsumoto, N. \& Rhoton Jr., A. L. The accuracy of an electromagnetic navigation system in lateral skull base approaches. Laryngoscope, 127(2):450-9, 2017.

Krayenbühl, N.; Isolan, G. R. \& Al-Mefty, O. The foramen spinosum: a landmark in middle fossa surgery. Neurosurg. Rev., 31(4):397-401, 2008 .

Lang, J.; Maier, R. \& Schafhauser, O. Postnatal enlargement of the foramina rotundum, ovale et spinosum and their topographical changes. Anat. Anz., 156(5):351-87, 1984.

Miller, R. S. \& Pensak, M. L. The superior petrosal triangle as a constant anatomical landmark for subtemporal middle fossa orientation. Laryngoscope, 113(8):1327-31, 2003.

Patil, J.; Kumar, N.; Rao, K. G. M.; Ravindra, S. S.; Somayaji, S. N.; Nayak, S. B.; Marpalli, S. \& Ashwini, L. S. The foramen ovale morphometry of sphenoid bone in South Indian population. J. Clin. Diagn. Res., 7(12):2668-70, 2013.

Peris-Celda, M.; Graziano, F.; Russo, V.; Mericle, R. A. \& Ulm, A. J. Foramen ovale puncture, lesioning accuracy, and avoiding complications: microsurgical anatomy study with clinical implications. J. Neurosurg., 119(5):1176-93, 2013.

Peris-Celda, M.; Perry, A.; Carlstrom, L. P.; Graffeo, C. S.; Driscoll, C. L. W. \& Link, M. J. Key anatomical landmarks for middle fossa surgery: a surgical anatomy study. J. Neurosurg., 131:1561-70, 2019.

Rhoton Jr., A. L. Navigating the temporal bone. Part 1 of 3. Rhoton Collection, YouTube, 2011. Available from: https://www.youtube.com/ watch?v=AEIKqKh752g
Rhoton Jr., A. L. The temporal bone and transtemporal approaches. Neurosurgery, 47(3 Suppl.):S211-65, 2000.

Roland, P. S.; Meyerhoff, W. \& Mickey, B. Management of the external auditory canal in skull base surgery. Skull Base Surg., 1(1):39-42, 1991.

Sennaroglu, L. \& Slattery 3rd, W. H. Petrous anatomy for middle fossa approach. Laryngoscope, 113(2):332-42, 2003.

Tanriover, N.; Sanus, G. Z.; Ulu, M. O.; Tanriverdi, T.; Akar, Z.; Rubino, P. A. \& Rhoton Jr., A. L. Middle fossa approach: microsurgical anatomy and surgical technique from the neurosurgical perspective. Surg. Neurol., 71(5):586-96, 2009.

\author{
Corresponding author: \\ Assoc. Dr. Esin Ozsahin \\ Baskent University \\ Faculty of Medicine \\ Department of Anatomy \\ 01330 Yuregir \\ Adana \\ TURKEY
}

E-mail :ozsahine@gmail.com

Received : 14-06-2021

Accepted : 02-09-2021 